FROM THE THIRD GENEVA CONFERENCE ON PERSON-CENTERED MEDICINE: SPECIAL INITIATIVES FOR PERSON-CENTERED CARE

\title{
Person-centred Psychodynamic Perspectives
}

\author{
Margit Schmolke PhD \\ Psychologist, Psychoanalyst, German Academy for Psychoanalysis, Munich, Germany
}

\begin{abstract}
A psychodynamic approach is person-centred in its deep sense as it applies to the person with his/her unique personality and life history. Psychodynamic skills and experiences help to understand symptoms not just as dysfunctions and deficits but as dynamic phenomena with their own understandable function and logic. Psychodynamic expertise helps to deal with complex decisions in diagnosis and treatment. In addition, a psychodynamic approach is context-oriented as it includes a perspective to the complexity of a health care situation. Unconscious processes and communication take place virtually everywhere in different clinical settings, e.g. in the therapist-patient relationship, in the whole atmosphere of a hospital unit, and among colleagues. Therefore, it is useful to understand difficult situations and communication problems in daily clinical work by applying psychodynamic skills (e.g., self-reflection and self-monitoring of transference and counter-transference feelings). This could take place in supervision groups, case conferences or staff meetings of an interdisciplinary team in medical settings, such as surgical, emergency unit, general medicine, liaison medicinal, and psychiatric settings.
\end{abstract}

\section{Keywords}

Psychodynamic skills in various clinical settings, unconscious, transference, counter-transference

\section{Correspondence Address}

Dr Margit Schmolke, German Academy for Psychoanalysis (DAP), Goethestr. 54, 80336 Munich, Germany. E-mail margitschmolke@aol.com

Accepted for publication: 18 February 2011

\section{Introduction}

The basic concepts of person-centered psychodynamics have been developed within the framework of psychoanalysis beyond an orthodox biological thrive theory perspective. These developments are characterized by an interpersonal approach with an intra-psychic and inter-psychic interaction within its total context, by the object relation theory [e.g.1,2], by an empathic therapeutic approach (instead of neutrality) [e.g.3,4], and by the inclusion of current results of attachment theory [e.g.5,6], and of brain research [e.g.7-10].

The Berlin School of Dynamic Psychiatry [11,12], to which the author belongs, has integrated these newer developments of psychoanalysis and includes furthermore the concept of group dynamics being useful not only for individual but also for group treatment as well as for communication in general with access to underlying unconscious dynamics. This concept has been applied by a diverse range of mental health professionals within the World Association of Dynamic Psychiatry (WADP) which is an international organization with the aim of applying and promoting a psychodynamic approach in psychiatry and other mental health areas. The WADP was founded in 1980 and is an affiliated member of the World Psychiatric Association (WPA).

\section{A psychodynamic approach is person-centered in its deepest} sense

A psychodynamic approach is person-centred in its deep sense as it applies to the person with his/her unique personality and unique life history. A psycho-dynamically oriented professional understands symptoms not just as dysfunctions and deficits, but as dynamic phenomena with their own understandable function and logic. It is argued that it is not the main goal to diagnose a psychiatric disorder according to symptoms, course and history, but rather to understand the person with the disorder and the person's capacity to recover from the disorder [13]. In simple words: If it is possible to understand and analyze

The International Journal of Person Centered Medicine Volume 1 Issue 1 pp 105-108 
the underlying logic of a patient's symptom, the symptom may disappear, because it will lose its necessity $[4,11]$.

\section{A psychodynamic expertise helps to deal with complex decisions in diagnosis and treatment}

In clinical diagnosis, it is important for the clinician to listen well to the patient's presentation of his current problems, why he/she asks for professional help at this moment of his/her life, to be attentive to non-verbal communication, to pay attention to the patient's own understanding of his/her problems as well as to his/her self-help potential. Jacobson and Cooper [14] from Cornell University Medical Center, New York, define a psychodynamic diagnosis in the following way:

\section{"Psychodynamic diagnosis, while taking full account of descriptive diagnostic data, attends as well to unconscious mental processes and the severity of maladaptation. It classifies core aspects of character, personality, and adaptation to life as they are revealed in different modes of relating and representing self and others, both consciously and unconsciously. (...) Psychoanalytic diagnosis is derived from the phenomenology of the interaction between analyst and patient, as well as from historical data of the life narrative."}

This way, psychodynamic diagnosis could be understood as a "joint interactive reconstruction process" [15] in which subjective suffering as well as positive mental health have their central place opposed to standardized classification systems $[16,17]$. In recent years, innovative psychodynamic diagnostic instruments have been developed [e.g. 18; in German speaking countries 19] in order to enhance the knowledge and the understanding of a patient's complex problem. The OPD, developed for German speaking countries, provides useful operationalisations of psychodynamic concepts and categories in order to assess patients' illness behaviour, their behaviour in interpersonal relationships, inner conflicts and the level of the personality structure.

Concerning treatment, it can be said in very general terms that by developing insight into the unconscious functions of symptoms and problems, the patient will be able to deal more successfully with life's problems, such as relationship problems, anxieties, adaptation or dependency conflicts. A psychodynamic treatment is a complex process and often needs more time than just symptom-oriented and behaviour-oriented treatments, especially for personality disorders [20-23]. We can say that a sophisticated knowledge of transference, counter-transference, and resistance is extraordinarily helpful in clinical work, including the practice of pharmacotherapy [4].
Psychodynamic therapists [e.g.4,12,24] have pointed out that the effectiveness of treatment is impaired when team members respond in the same manner as though they are the patient's parents. It is well-known that hospitalized psychiatric patients are significantly more stressed than outpatients, they tend to employ more immature defence mechanisms like splitting, projective identification than mature ones. The patients unconsciously repeat and direct their internalized object relations and conflicts to the persons in the psychiatric milieu. Therapists with clinical experience and with a psychodynamic background know that dealing with these defence mechanisms and transference feelings is quite challenging, even more for residents at the beginning of their career.

Furthermore, there are essential preventive aspects in applying a psychodynamic approach. Since a psychodynamic treatment has its focus on the development of the patient's personality, it could prevent patients from having relapses, from discontinuing their treatment, and from developing a chronic and severe psychopathology. Staff members working in demanding and challenging psychiatric wards could benefit from a psychodynamic understanding of complex clinical problems and be prevented from developing a burnout syndrome [25].

\section{A psychodynamic approach is also context-related}

A psychodynamic approach is context-oriented as it provides a perspective to the interpersonal complexity of a clinical care situation. A psychodynamic approach can be understood as a way of thinking by the therapist, not only about one's patients, but also about oneself in the interpersonal field between patient and the treating professional or between the patient and the treatment staff as a whole. Unconscious processes and communication take place virtually everywhere in different clinical settings, e.g. in the therapist-patient relationship, in the whole atmosphere of a hospital unit, and among colleagues. Therefore, it is useful to understand difficult situations and communication problems in daily clinical work by applying psychodynamic and group-dynamic skills, for example, through self-reflection and selfmonitoring of transference and counter-transference feelings [26]. The application of a psychodynamic perspective is not only useful in the classical treatment situation, but also in supervision groups, in case conferences or staff meetings of an interdisciplinary team in medical settings, such as surgical, emergency unit, in general medical, liaison medicine, and psychiatric settings.

Peykan Gökalp from the Bakirkoy Hospital for Psychiatry, Istanbul, organized an interesting symposium in Thessaloniki, Greece, in September 2007, on the topic "Psychoanalytic perspectives in different settings". The authors of this symposium presented their views about the application of psychodynamic concepts to patients of a 
general hospital, to patients and staff members of a large psychiatric hospital, to the treatment of psychotic patients and eating disorder patients. In her paper, Peykan Gökalp [26] pointed out that, sometimes, therapeutic teams or single staff members may have unconscious, idealized wishes towards their institution or towards the medical director of a large psychiatric hospital who should manage everything ideally like an omnipotent father figure and if their expectations are not fulfilled they may react with disappointment, frustration, or anger.

Outside of a definitive individual psychotherapy setting, we daily observe unconscious communication between health professionals and patients. Especially in stress situations or in interaction with a patient who is expressing intense feelings, negative chain reactions between a patient and a therapeutic team could be the consequence of their communication. Often transference and counter-transference occur in such situations. Transference feelings are unconscious feelings (positive or negative ones) of the patient towards the therapist which originally have been directed to persons in early childhood, e.g. to the patient's parents. Working with transference feelings belongs to the therapist's basic tools. However, transference feelings which take place outside of a patienttherapist relationship, for example of a team member, could have quite destructive consequences for clinical decisions, when this team member directs his other hostile feelings towards his superior.

The unconscious response to these transference feelings is called counter-transference. This term means the totality of unconscious reactions of the therapist to his patient, particularly to his transference feelings. Volkan Topcuoglu [27], from the Marmara University School of Medicine, Istanbul, suggests a broader definition of counter-transference, since it is beneficial for both psychiatrists and psychiatry residents as a major diagnostic and therapeutic tool. By comprehending his countertransference towards the patient, a psychiatry resident can understand a great deal about the patient's internal world. Furthermore he would be able to explore further the possible reactions of 'significant others' towards the patient. The ongoing task for a psychiatry resident during a psychiatric treatment should therefore be to recognize and to monitor continuously his own counter-transference feelings. If this does not happen, a therapist is likely to overreact to his patients or to make clinical decisions with negative results (e.g., forgetting appointments, labelling a patient as "non-compliant" or "anti-social”). Another example could be over-medication as a consequence of unconscious and not realized counter-transference feelings of a therapist (such as helplessness) towards a patient who is not cooperative.

In any case, a psycho-dynamically oriented supervision should be provided in each therapeutic team. It could be beneficially educative for residents in order to raise awareness and to gain control in complex situations. Since the provision of supervision is not always available, residents will experience their counter-transference feelings as uncomfortable and as disruptive elements in their therapeutic work. The consequence may be that they inevitably withdraw and possibly avoid psychodynamic concepts and psychotherapies. Sadly in times of costeffective treatment, and pharmacotherapy, and time-limited therapy settings, such incidents of withdrawal and avoidance are far more likely to take place.

\section{Conclusions}

In recent years, we have observed an interesting emergence of theoretical perspectives in various schools of psychotherapy. Clinicians with a great deal of therapeutic experience appear to have come to the conclusion that the sharp demarcation between the concepts of psychotherapeutic schools is no longer useful. They seem to appreciate that clinicians of different psychotherapeutic schools may benefit from each other's experience and knowledge. For example, psychoanalytic clinicians recognize that a personality change at the end of a successful course of psychotherapy may also imply a change of the person's behaviour. And, vice versa, cognitive behaviour therapists recognize that the patienttherapist relationship and unconscious dynamics play an important role in psychotherapeutic treatment.

From a clinical and training point of view, there is no doubt that a psychodynamic perspective is useful in clinical settings, in interdisciplinary staff meetings and for effective communication in mental health institutions and in health institutions in general. Future plans and designs for quality improvement could be the following:

- The development of a curriculum to teach personcentred psychodynamics

- Teaching interdisciplinary staff members of a medical, psychosomatic or psychiatric hospital unit or of medical private practices

- Providing supervision to health care workers on the basis of psycho- and group-dynamic principles

- A possible collaboration project between the International Network of Person-Centered Medicine (INPCM), WADP and the Section on "Psychoanalysis in Psychiatry" of the World Psychiatric Association (WPA).

\section{References}

[1] Fairbairn, W.R.D. (1952). Object relationships and dynamic structure. In: Psychoanalytic studies of the personality (W.R.D. Fairbairn), pp. 137-151. London: Tavistock.

[2] Winnicott, D.W. (1965). The family and individual development. London: Tavistock.

[3] Ferenczi, S. (1988). Ohne Sympathie keine Heilung. Das klinische Tagebuch von 1932. Frankfurt/M: S. Fischer. Original edition: Journal Clinique, 1985, Paris: Payot. 
[4] Gabbard, G.O. (2005). Psychodynamic Psychiatry in Clinical Practice. 4th Ed. Arlington, VA: American Psychiatric Publishing.

[5] Bowlby, J. (1988). A secure base. London: Routledge.

[6] Fonagy, P. (2001). Attachment theory and psychoanalysis. New York: Other Press.

[7] Schore, A.N. (2002). Dysregulation of the right brain: A fundamental mechanism of traumatic attachment and the psychopathogenesis of posttraumatic stress disorders. Australian and New Zealand Journal of Psychiatry 36, 9 - 30.

[8] Schore, A.N. (2003). Affect Regulation and the Repair of the Self. New York: W.W. Norton \& Company.

[9] Joseph, R. (1992). The right brain and the unconscious: Discovering the stranger within. New York: Plenum Press.

[10] Kandel, E.R. (2005). Psychiatry, Psychoanalysis and the New Biology of Mind. Washington, D.C.: American Psychiatric Publishing.

[11] Ammon, G. (1979). Psychosomatic illness as a result of a deficit in Ego-structure under consideration of the genetic, dynamic, structural and group-dynamic point of view. Psychotherapy and Psychosomatics 31, 179 - 189.

[12] Ammon, G. (1980). Ego-structural and groupdynamic aspects causing schizophrenia - methods for its treatment. Dynamische Psychiatrie / Dynamic Psychiatry 13, 429 - 450.

[13] Amering, M., Schmolke, M. (2009). Recovery in Mental Health. Reshaping scientific and clinical responsibilities. Chichester: Wiley-Blackwell.

[14] Jacobson, W., Cooper, A.M. (1993). Psychodynamic diagnosis in the era of the current DSMs. In: Psychodynamic Treatment Research. A Handbook for Clinical Practice. (eds N.E. Miller, L. Luborsky, J.P. Barber \& J.P. Docherty), pp 109-126. New York: Basic Books.

[15] Küey, L., Gürdal Küey, A. (2007). Diagnosis as a joint reconstruction process. Paper presented at the Section Symposium on "Psychodynamic essentials for a person-centered psychiatry", chaired by M Schmolke \& M Botbol, of the Sections on "Preventive Psychiatry" and on "Psychoanalysis in Psychiatry", at the WPA Regional Meeting, Melbourne, Nov 29 - Dec 2, 2007. [16] Mezzich, J.E., Salloum, I.M. (2009). Towards a Personcentred Integrative Diagnosis. In: Psychiatric Diagnosis. Challenges and Prospects (eds I.M. Salloum \& J.E. Mezzich), pp 297-302. Chichester: Wiley-Blackwell.

[17] Botbol, M., Berganza, C.E. (2009). Specifities in Diagnosis and Classification in Child and Adolescent Psychiatry. In: Psychiatric Diagnosis. Challenges and Prospects. (eds I.M. Salloum \& J.E. Mezzich), pp 147-154. Chichester: WileyBlackwell.

[18] Alliance of Psychoanalytic Organizations (2006). Psychodynamic Diagnostic Manual (PDM). Silver Spring, M.D.: Alliance of Psychoanalytic Organizations.

[19] Arbeitskreis OPD (Hrsg.)(2009). Operationalisierte Psychodynamische Diagnostik OPD-2. Das Manual für Diagnostik und Therapieplanung. 2., überarb. Aufl. Bern: Hans Huber.

[20] Ammon, M. (2008). The borderline personality disorder - a dynamic psychiatric view. Dynamische Psychiatrie / Dynamic Psychiatry 41, 229 - 242.

[21] Schmolke, M. (2007a). Psychodynamic essentials for a Person-centered psychiatry: Conceptual perspectives. Paper presented at the Section Symposium on "Psychodynamic essentials for a person-centered psychiatry", chaired by $\mathrm{M}$ Schmolke \& $\mathrm{M}$ Botbol, of the Sections on "Preventive Psychiatry" and on "Psychoanalysis in Psychiatry", at the WPA Regional Meeting, Melbourne, Nov 29 - Dec 2, 2007.

[22] Perry, J., Banon, E., Floriana, I. (1999). Effectiveness of psychotherapy for personality disorders. American Journal of Psychiatry 156,1312 - 21.

[23] Luborsky, L. (1984). Principles of psychoanalytic psychotherapy: A manual for supportive-expressive treatment. New York: Basic Books.

[24] Alanen, Y.O. (1997). Schizophrenia. Its Origins and NeedAdapted Treatment. London: Karnac Books.

[25] Schmolke, M. (2007b). The contribution of the psychodynamic approach to the prevention of psychopathology. Psychiatry Today 39 (1), 31 - 37.

[26] Gökalp, P.G. (2007). Psychoanalytic perspective in a large psychiatric hospital: Is "institutional psychoanalysis" possible? Paper presented within a symposium on "Psychoanalytic Perspective in Different Settings", chaired by P. Gökalp \& N. Tzavaras, at the First Eastern European Congress of Psychiatry, Thessaloniki, September 21-23, 2007.

[27] Topcuoglu V (2006): Counter-transference in the hospital: A therapeutic tool for residents. Paper presented within the Symposium of the WPA Section "Psychoanalysis in Psychiatry" on the topic "An unspoken reality in psychiatry: Countertransference issues", at the World Psychiatric Association International Congress, Istanbul, July 12-16, 2006. 